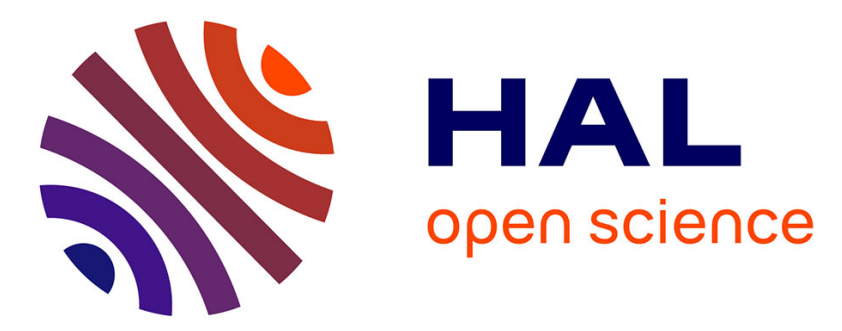

\title{
Buried targets detection from synthetic anc measured B-scan ground penetrating radar data
}

Xiang Liu, Mohammed Serhir, Abelin Kameni, Marc Lambert, Lionel Pichon

\section{To cite this version:}

Xiang Liu, Mohammed Serhir, Abelin Kameni, Marc Lambert, Lionel Pichon. Buried targets detection from synthetic anc measured B-scan ground penetrating radar data. 11th European Conference on Antennas and Propagation (EuCAP 2017), Mar 2017, Paris, France. pp.1726 - 1730, 10.23919/EuCAP.2017.7928686 . hal-01587755

\section{HAL Id: hal-01587755 \\ https://hal-centralesupelec.archives-ouvertes.fr/hal-01587755}

Submitted on 15 Sep 2017

HAL is a multi-disciplinary open access archive for the deposit and dissemination of scientific research documents, whether they are published or not. The documents may come from teaching and research institutions in France or abroad, or from public or private research centers.
L'archive ouverte pluridisciplinaire HAL, est destinée au dépôt et à la diffusion de documents scientifiques de niveau recherche, publiés ou non, émanant des établissements d'enseignement et de recherche français ou étrangers, des laboratoires publics ou privés. 


\title{
Buried Targets Detection from synthetic and measured B-scan Ground Penetrating Radar Data
}

\author{
X. Liu, M. Serhir, A. Kameni, M. Lambert, L. Pichon \\ GeePs - Group of electrical engineering - Paris, UMR CNRS 8507, CentraleSupélec, Univ. Paris-Sud, Université Paris-Saclay, \\ Sorbonne Universités, UPMC Univ Paris 06 \\ 3 \& 11 rue Joliot-Curie, Plateau de Moulon 91192 Gif-sur-Yvette CEDEX, France, Xiang.liu@ centralesupelec.fr
}

\begin{abstract}
The localization of buried targets using Ground Penetrating Radar (GPR) is dealt with. The bi-static GPR is made of two identical Vivaldi antennas operating from $1 \mathrm{GHz}$ to $3.5 \mathrm{GHz}$ and installed in front of a sand box. The experimental data acquired in a controlled laboratory environment are validated by electromagnetic simulation. Then, both synthetic and experimental data are processed to detect the buried targets via three migration methods. The targets localization is achieved from the GPR B-scan data. The results obtained via Stripmap SAR, Frequency-Wavenumber $(\mathrm{F}-\mathrm{K})$ migration and Kirchhoff migration are presented and compared.
\end{abstract}

Index Terms -GPR, imaging, migration, measurement.

\section{INTRODUCTION}

The use of Ground-Penetrating Radar (GPR) has been developed in an extended number of applications for many years. The GPR technique is used in geophysics and civil engineering to provide effective and accurate imaging of underground structures and for buried objects detection. It still needs development as shown by the recent COST Action TU1208 "Civil Engineering Application of Ground Penetrating Radar" [1], [2], [3]. Therefore, it is interesting to explore the GPR performance for estimating the target location.

The B-scan GPR radargram is a space-time image. It represents the chronological happening of the echoes due scatterers as a function of the measurement position along a line. Any scatterer contained in the measured region appears on the radargram as a hyperbola due the different travel times of the electromagnetic wave while the antenna scan along a line. The migration techniques are the traditional GPR imaging tools to focus the target signature onto its actual position. They provide a relatively high-resolution images enabling to localize the targets [4], [5].

Here, three imaging techniques results are compared: Stripmap synthetic aperture radar (SAR), Kirchhoff migration (KM) and Frequency-Wavenumber migration (F-K). We start with a single target detection and then we dealt with two buried targets very close to each other. The B-scan GPR data are obtained through the measurements in the Centralesupelec anechoic chamber and using the electromagnetic simulation software CST MICROWAVE STUDIO (CST-MWS). The same configurations are measured and numerically modeled in CST.

The paper is organized as follows: in section II, the GPR scenarios are presented and the results of simulation and measurement are compared. In section III the imaging results of the different migration methods are presented and, in section IV some conclusions are drawn.

\section{GPR SYSTEM SETUP AND B-SCAN DATA}

\section{A. GPR system setup}

The bi-static GPR is made of two identical Vivaldi antennas which are widely used for GPR applications. Its structure is shown in Fig. 1. The two antennas (transmitter/receiver) are placed face to face and separated by $100 \mathrm{~mm}$ (Fig. 2(a) and Fig. 2(b)). They are fixed via a polystyrene support $\left(\epsilon_{r}=1\right)$ on a displacement system to move at the desired height and
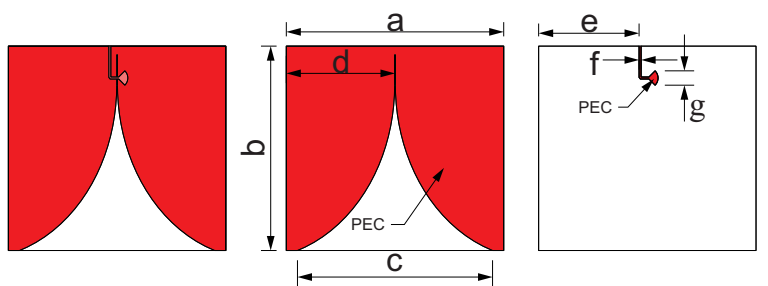

Fig. 1. Sketch of the used Vivaldi antenna. $a=150.0 \mathrm{~mm}, b=141.0 \mathrm{~mm}, c=134.6 \mathrm{~mm}, d=75.0 \mathrm{~mm}, e=69.3 \mathrm{~mm}, f=1.4 \mathrm{~mm}$ and $g=9.9 \mathrm{~mm}$. 

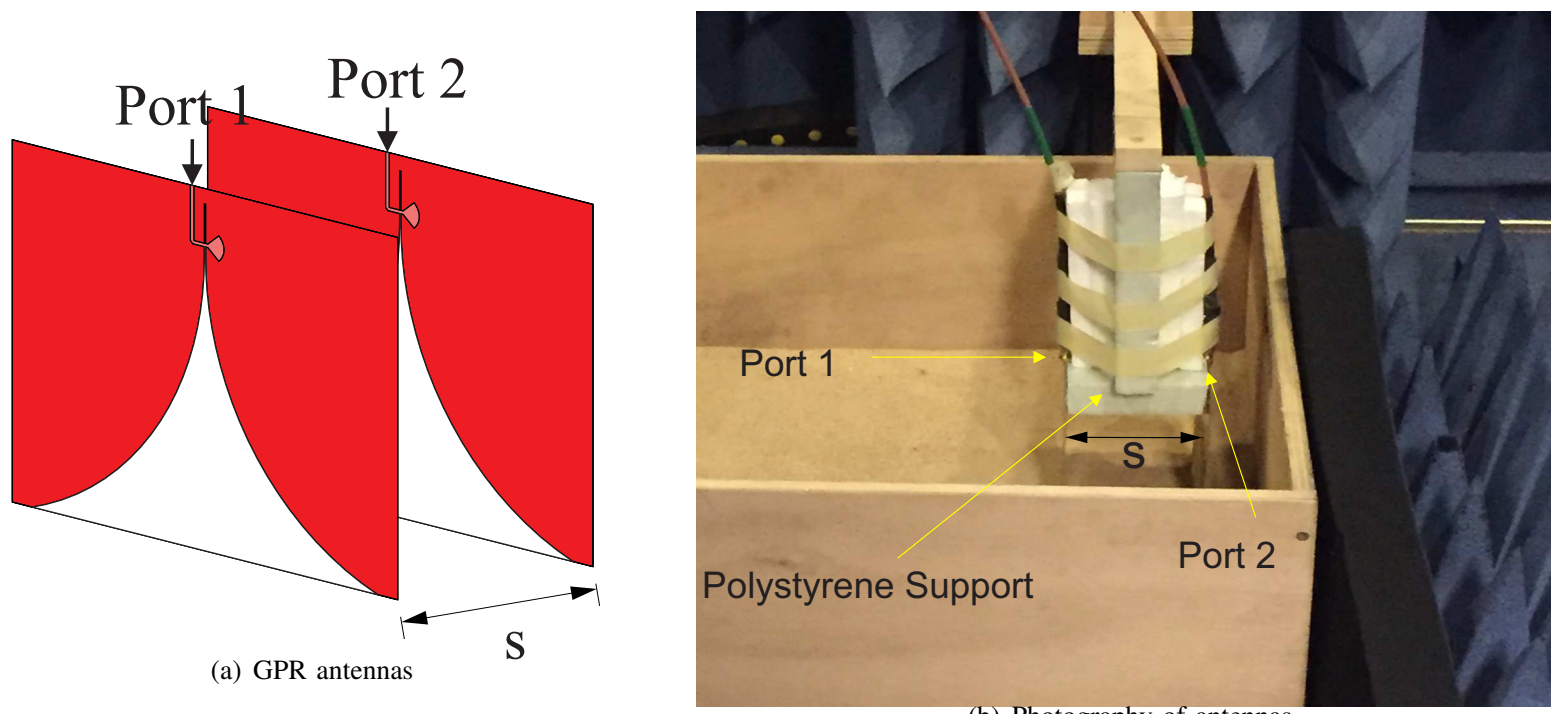

(b) Photography of antennas

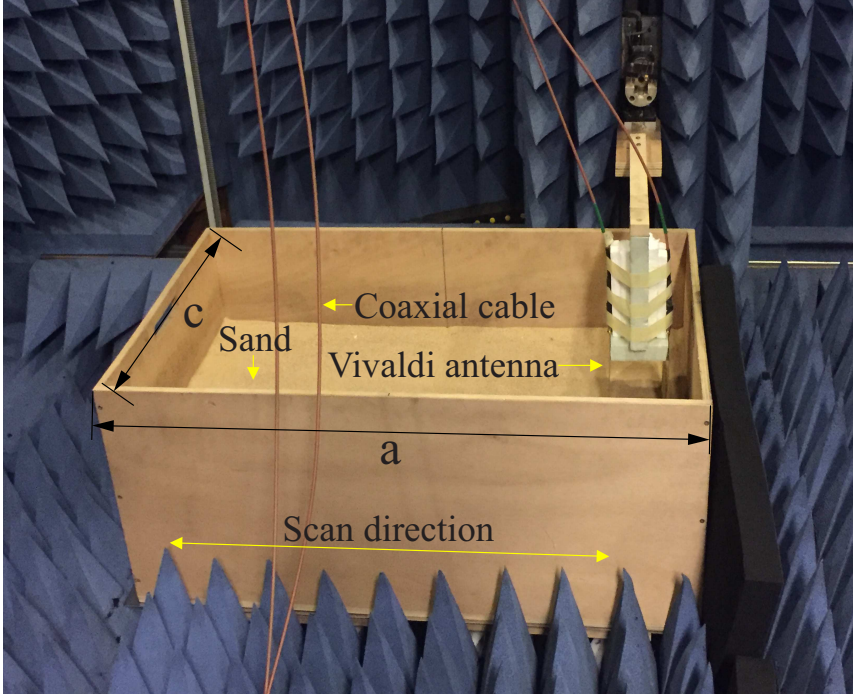

(c) Measurement system

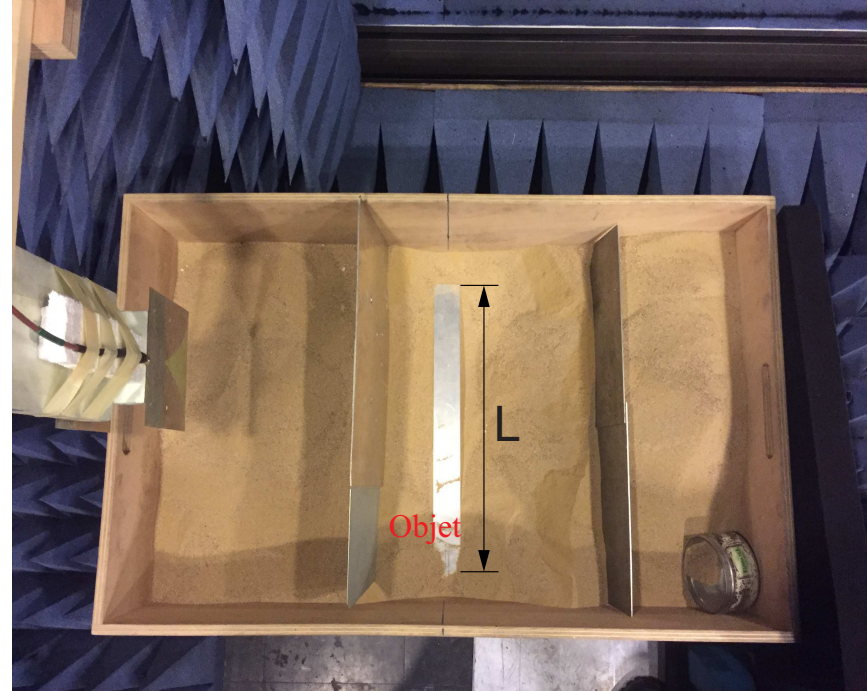

(d) Buried target

Fig. 2. GPR antenna (a) and photos of the measurement equipment (b) (c) (d). The dimensions of the system: $a=1000 \mathrm{~mm}, c=600 \mathrm{~mm}, L=500 \mathrm{~mm}$, $S=100 \mathrm{~mm}$.

position. The B-scan data are obtained by moving the antennas along a line while measuring the $S_{12}$ parameters for 128 steps from $500 \mathrm{MHZ}$ to $3.5 \mathrm{GHz}$ (Fig. 2(b)). Indeed, we have used a step frequency continuous wave strategy to acquire the data using the Agilent E5071B ENA Vector Network Analyzers.

The sand-filled wooden box is placed over a metal plate in order to eliminate uncontrollable reflections resulting from the support of the box and the soil floor. The sand is dry and its measured relative permittivity is almost constant around $\epsilon_{r}=2.53$ between $500 \mathrm{MHz}$ and $3.5 \mathrm{GHz}$. Two metal bars of the same length $(L=500 \mathrm{~mm})$ and of various shapes - one of square cross-section of size $D=50 \mathrm{~mm}$, the other of circular cross-section of diameter $\varnothing=50 \mathrm{~mm}-$ are buried in the sand. Their positions and the sandbox dimensions are indicated in the front view scheme of GPR scenarios in Fig. 3, where only the sand-filled part is depicted. The rectangular metal bar is horizontally placed at the center of the sandbox at a depth of $\mathrm{P}_{1}=$ $125 \mathrm{~mm}$ whereas the cylindrical metal bar is placed at a depth of $\mathrm{P}_{2}=95 \mathrm{~mm}$, the lateral distance between the two targets being $E=50 \mathrm{~mm}$. The center of the sandbox is considered as the origin and the B-scan displacement range going from $-200 \mathrm{~mm}$ to $200 \mathrm{~mm}$ with a step of $20 \mathrm{~mm}$.

The same configuration is considered in the simulation procedure with CST-MWS in which both the antennas and sandbox are modeled (3D model), the sand being considered as a homogeneous medium with $\epsilon_{r}=2.53$. The measured and simulated B-scan data are inverse Fourier transformed to obtain the radargram. The time domain excitation signal is considered as a 


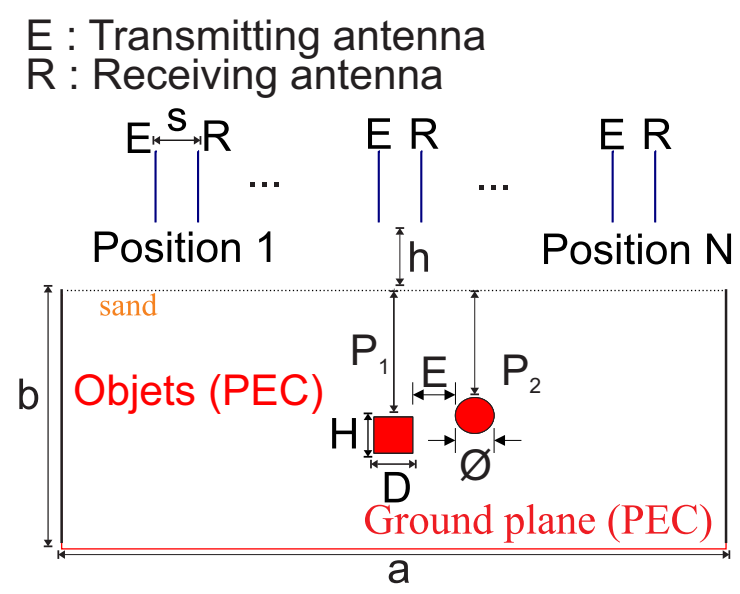

Fig. 3. Front view scheme of GPR scenarios. $a=1000 \mathrm{~mm}, b=210 \mathrm{~mm}, c=600 \mathrm{~mm}, H=50 \mathrm{~mm}, D=50 \mathrm{~mm}, L=500 \mathrm{~mm}, P_{1}=125 \mathrm{~mm}$, $\varnothing=50 \mathrm{~mm}, P_{2}=95 \mathrm{~mm}, E=50 \mathrm{~mm}, S=100 \mathrm{~mm}, h=2 \mathrm{~mm}$.

Sine-Gaussian pulse given by:

$$
s(t)=A \cdot \exp \left(-\left(\frac{t-\tau}{T}\right)^{2}\right) \cdot \sin \left(2 \pi f_{0} \cdot(t-\tau)\right)
$$

where $\mathrm{A}$ is the normalization coefficient, $\tau$ the shift time, $f_{0}$ denotes the central frequency and the frequency range is determined by $T$.

\section{B. Numerical and experimental results}

Firstly, we study a GPR scenario with the square cross-section metal bar only. The configuration parameters are the same as in Fig. 3. The $S_{12}$ parameter obtained by measurement and by simulation at $x=0$ is displayed Fig. 5 and shows a good agreement.

The radagrams obtained from measurements and CST-MWS simulations are presented in Fig. 4. The incident field is obtained by measuring or modeling the sandbox without the buried object. The scattered field is the difference between the total and incident fields. The total field radargarm (Fig 4(b)) chronologically presents the reflections due to the air/sand interface and antennas coupling, then, the buried metallic object and finally, the bottom metal plate placed under the sandbox whereas, in the scattered field radargram (Fig 4(c)), the reflection due to the sand surface and the antennas coupling disappear, only remain the signatures of the target and its shade due the metal plate.

In the second configuration, the two metal bars are buried in the sand as shown in Fig. 3. The total and scattered field radagrams obtained using the measurement and the CST-MWS simulations are displayed in Fig. 6. In this case, the signatures of two targets are overlapping, since they are close to each other, however a good agreement between simulation and experimentation is obtained in these configurations as well.

\section{GPR IMAGING FOR BURIED OBJECTS DETECTION}

As shown in section II, the B-scan radargram delineates the scatterer as a hyperbola signature with a limited resolution. In this section, three imaging techniques are applied to attempt to localize the targets.

\section{A. Stripmap Synthetic Aperture Radar (SAR)}

Conventional synthetic aperture radar (SAR) imaging techniques are based on the convolution of the received data with the inverse of the point target response. The Stripmap SAR is a more sophisticated SAR-type algorithm, its formulation being found in [6] for example. A stripmap SAR imaging code is developed and applied for our application either on the total field data or on the scattered field data. The imaging results for the single buried target configuration being displayed in Fig. 7 and exhibits a better signature of the scatterer.

The imaging results via Stripmap SAR for two buried objects configuration are shown in Fig. 8. The imaging with scattered field data (Fig. 8(b)) shows a better localization of the two targets with respect to the one obtained using the total field (Fig. 8(a)). The similarity of imaging for simulated and measured data validate our measurement, therefore only the experimental data imaging will be shown hereafter. 

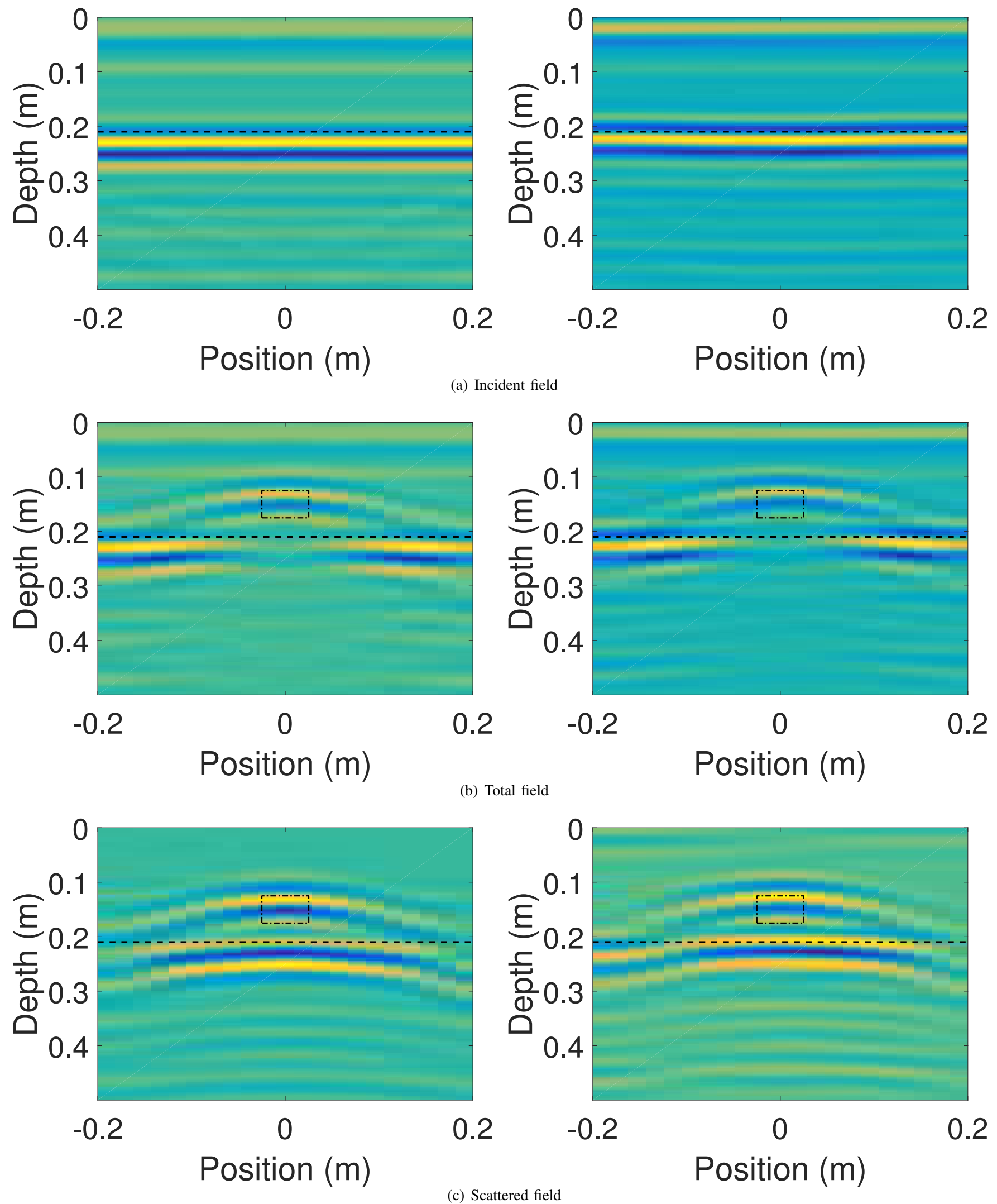

Fig. 4. Radagrams with one buried object : CST-MWS (left) and measurement (right), the dash-dot contour present the exact position of buried object, the dashed line is the bottom metal plate. 


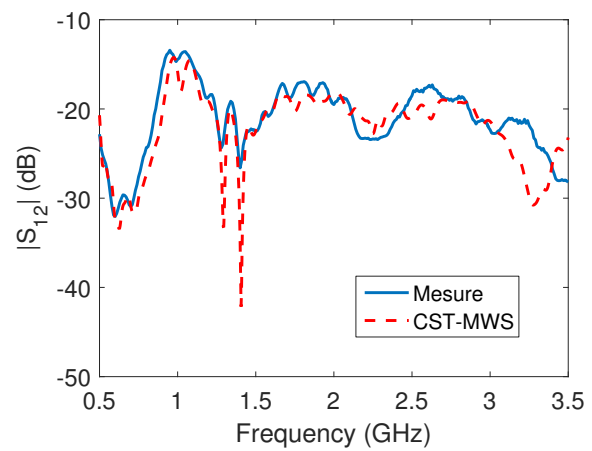

Fig. 5. Simulated and measured $S_{12}$ parameter at $x=0$ for the single buried target configuration
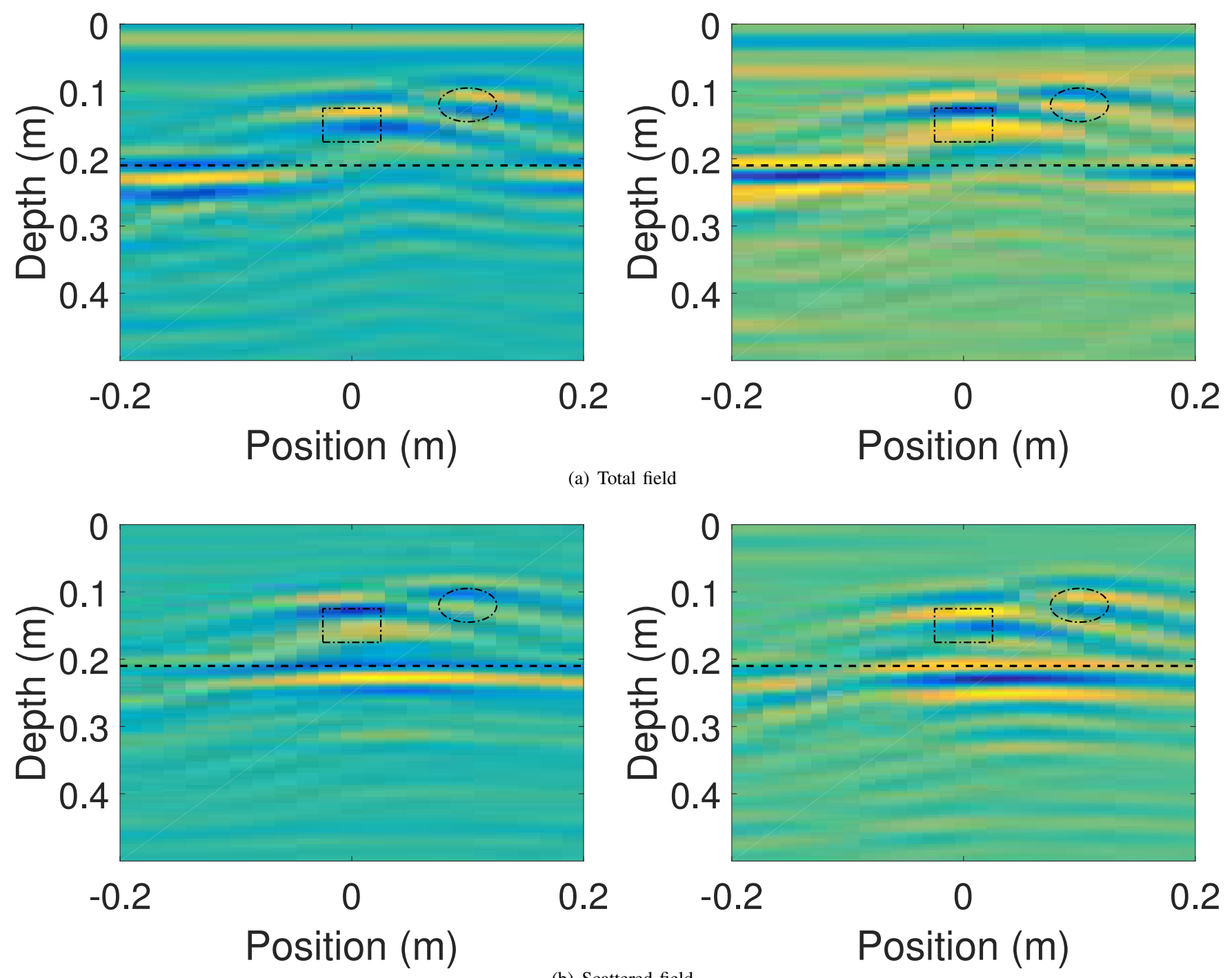

(b) Scattered field

Fig. 6. Radagrams with two buried objects : CST-MWS (left) and measurement (right), the dash-dot contour present the exact position of buried objects, the dashed line is the metal bottom plate. 

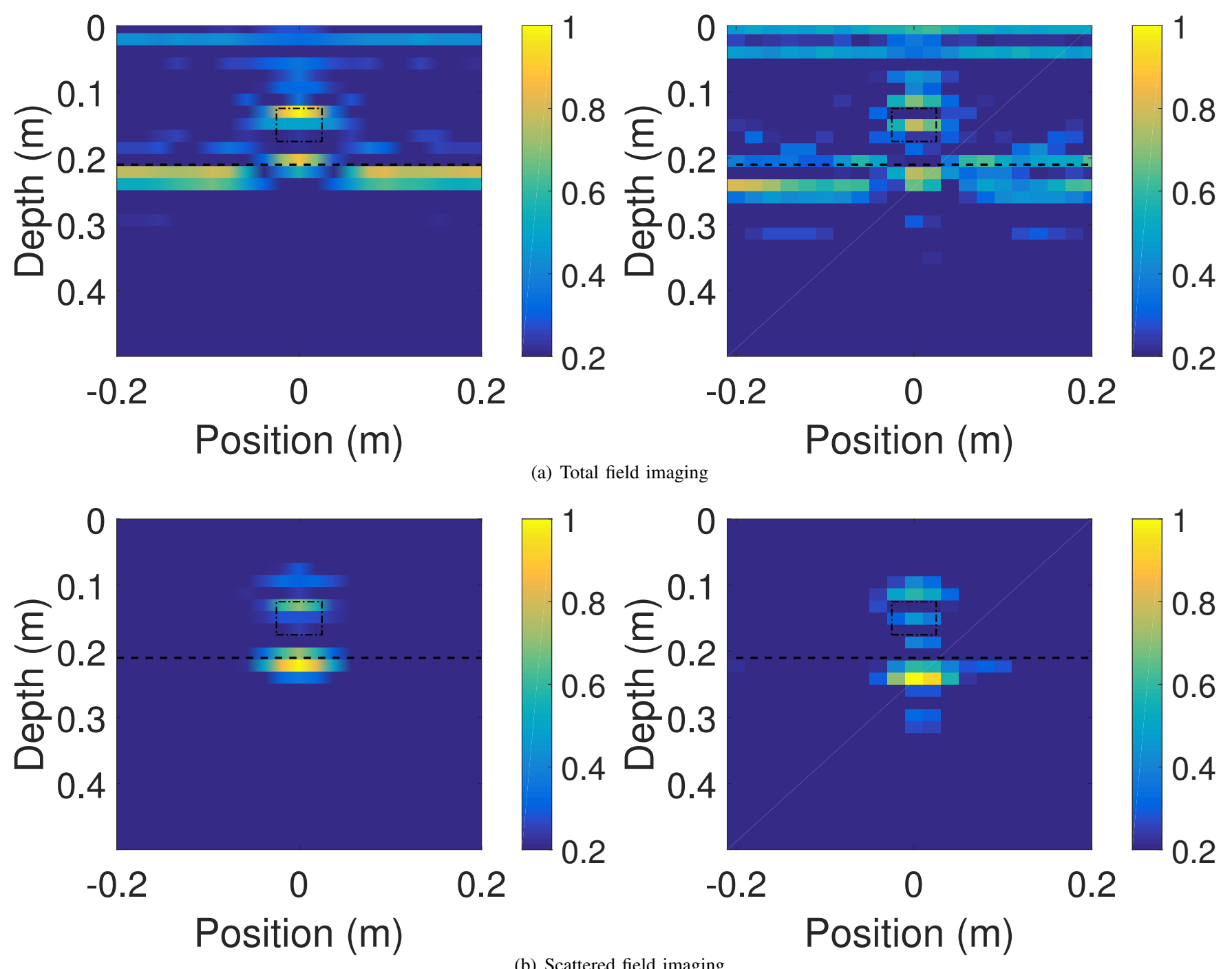

Fig. 7. Stripmap SAR imaging with a single buried object : CST-MWS (left) and measurement (right), the dash-dot contour present the exact position of buried objects, the dashed line is the metal bottom plate.

\section{B. Frequency-Wavenumber (F-K) Migration}

Frequency-wavenumber (F-K) was first introduced by Stolt [4]. It is based on a scalar wave equation model and the final result closely mirrors the final form of the stripmap SAR algorithm [6]. The F-K migration imaging of the single and the two buried targets configuration are shown in Fig. 9 and Fig. 10 respectively.

The F-K imaging results are quite similar to the Stripmap SAR ones and are suffering from the interference between the two targets and the bottom metal plate. Furthermore, in both algorithms, the pixel size of the reconstructed image is determined by the frequency and space displacement step of the B-Scan. In our case, the space displacement step is fixed to $20 \mathrm{~mm}$.

\section{Kirchhoff migration (KM)}

Kirchhoff migration (KM) is based on an integral solution of the scalar wave equation. It is performed by using the Kirchhoff integral representation of a field at a given point as a superposition of waves propagating from adjacent points and times [7]. Our KM imaging results are displayed in Fig. 11 and Fig. 12. The focusing is achieved after applying the KM to the measured GPR data. Unlike the Stripmap SAR and F-K imaging, the pixel size in KM is determined by the end-user, leading to a better resolution of the images.

\section{CONCLUSION}

In this paper, B-scan GPR data are obtained via either measurement or simulation in buried object scenarios and a good agreement between them is achieved. The synthetic and measured data are then used for GPR imaging using Stripmap SAR, 

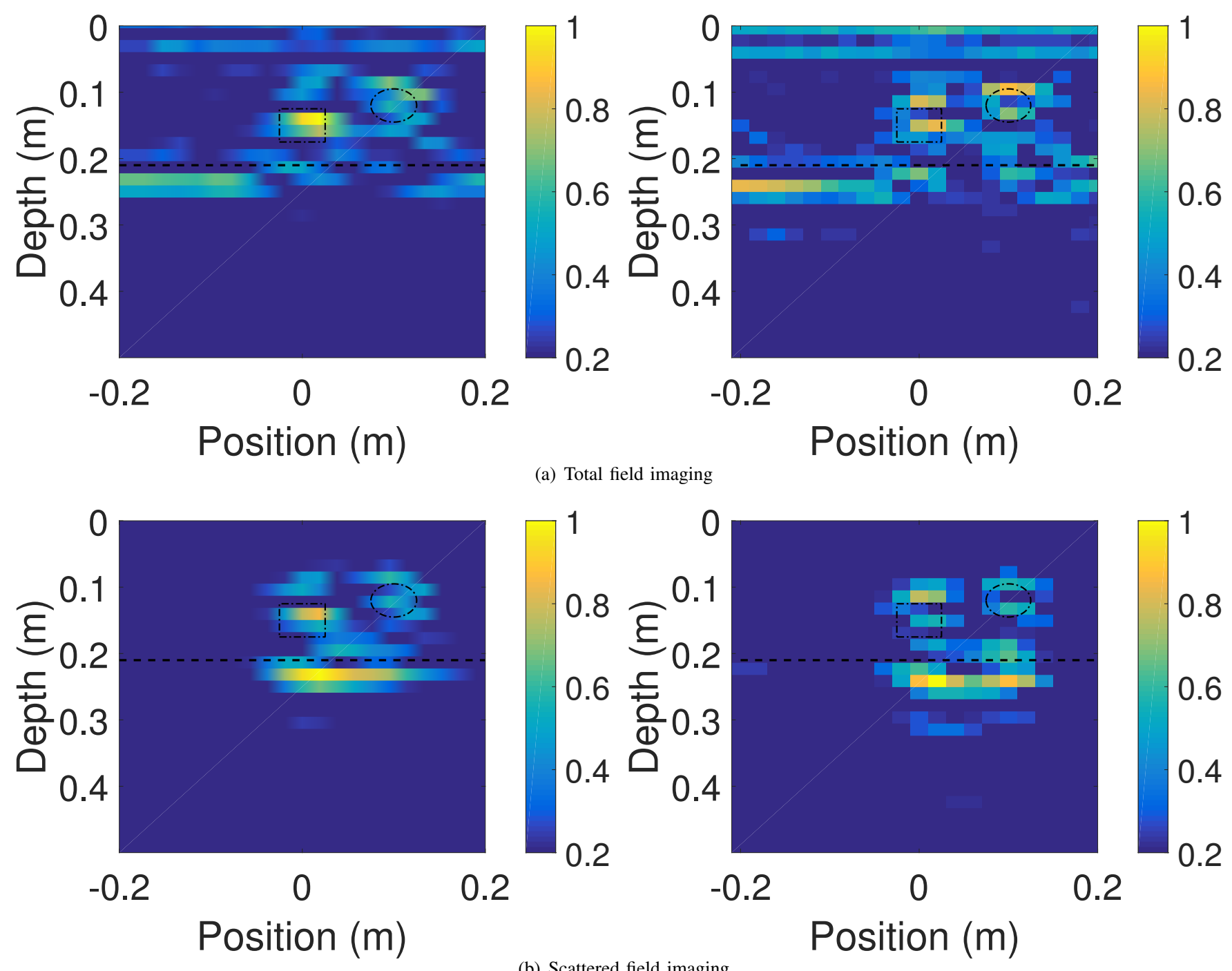

Fig. 8. Stripmap SAR imaging with two buried objects : CST-MWS (left) and measurement (right), the dash-dot contour present the exact position of buried objects, the dashed line is the grand plate.

F-K imaging and Kirchhoff migration and preliminary localization of one or two obstacles has been achieved. The presented imaging techniques does not provide any information about target shape and/or extention and are a first step toward some advanced imaging techniques such as an Enhanced Linear Sampling Method already developed by the authors in a free space configuration [8], [9] and currently under extension for the GPR application.

\section{ACKNOWLEDGMENT}

This research was carried out within the framework of EU funded COST Action TU1208 Civil Engineering Applications of Ground Penetrating Radar.

\section{REFERENCES}

[1] D. J. Daniels, Ground Penetrating Radar. Institution of Engineering and Technology (IET), 2004, vol. 1.

[2] L. Pajewski, A. Benedetto et al., "Applications of ground penetrating radar in civil engineering-COST action TU1208," in 7th IEEE International Workshop on Advanced Ground Penetrating Radar (IWAGPR), 2013, pp. 1-6.

[3] A. Benedetto and L. Pajewski, Civil Engineering Applications of Ground Penetrating Radar. Springer, 2015.

[4] R. Stolt, "Migration by fourier transform," Geophysics, vol. 43, no. 1, pp. 23-48, 1978.

[5] C. G. Gilmore, "A comparison of imaging methods using GPR for landmine detection and a preliminary investigation into the sem for identification of buried objects," Ph.D. dissertation, University of Manitoba, 2004.

[6] M. Soumekh, Synthetic Aperture Radar Signal Processing. New York: Wiley, 1999.

[7] J. Gazdag and P. Sguazzero, "Migration of seismic data," Proceedings of the IEEE, vol. 72, no. 10, pp. 1302-1315, 1984. 


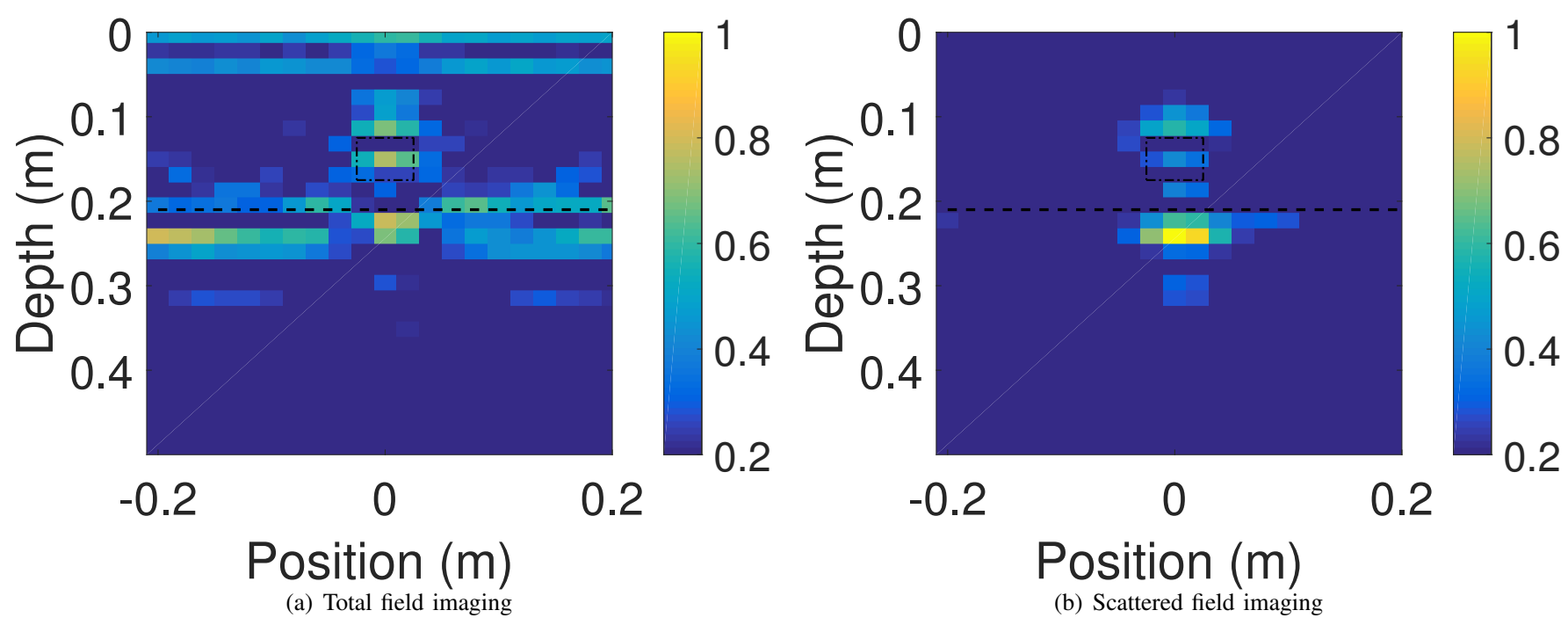

Fig. 9. F-K migration imaging with a single buried object from measured data: the dash-dot contour present the exact position of buried objects, the dashed line the bottom metal plate

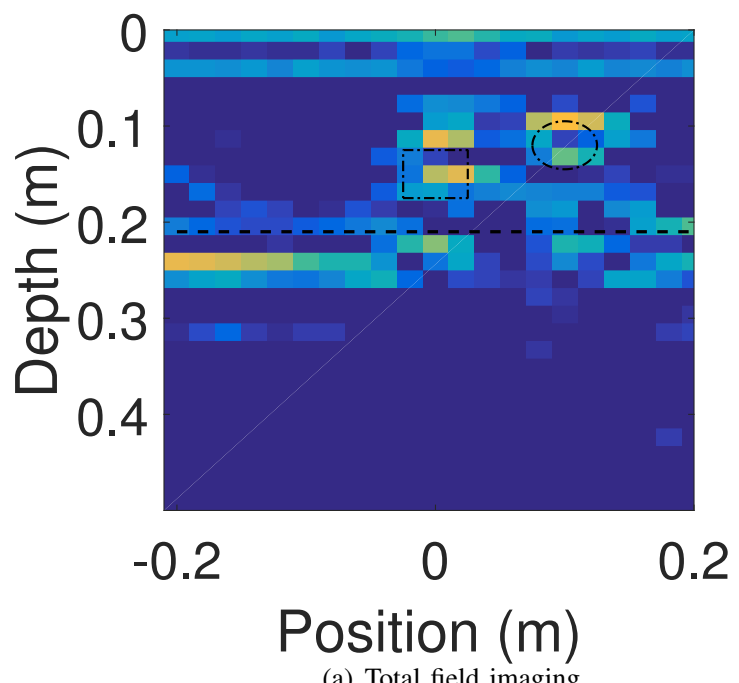

(a) Total field imaging

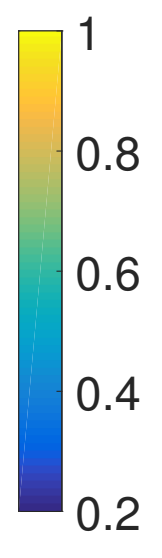

0.2

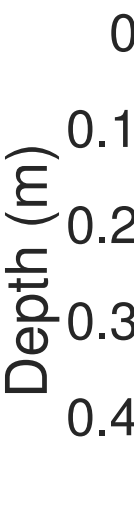

$-0.2$

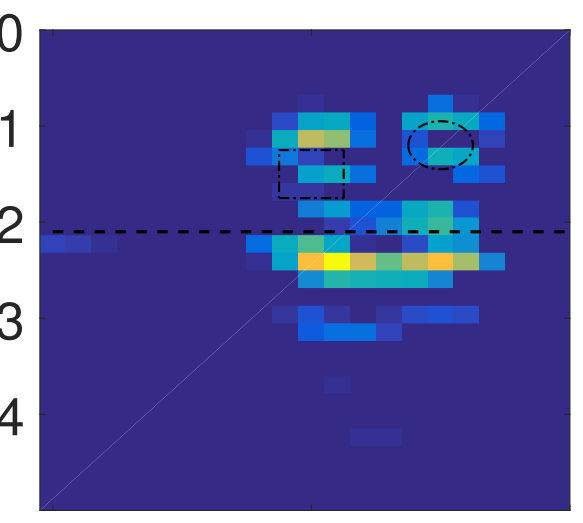

0

0.2

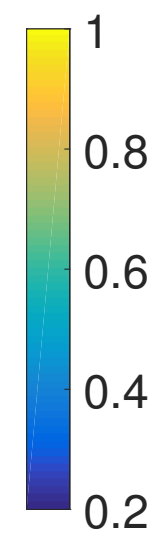

Position (m)

(b) Scattered field imaging

Fig. 10. F-K migration imaging with two buried objects from measured data: the dash-dot contour present the exact position of buried objects, the dashed line is the bottom metal plate.

[8] X. Liu, M. Serhir et al., "Enhanced linear sampling method for GPR imaging," in International Workshop on New Computational Methods for Inverse Problems (NCMIP 2016), Cachan, France, p. 4 pages.

[9] —_, "GPR imaging via multi-frequency linear sampling method," in 10th International Symposium on Electric and Magnetic Fields (EMF 2016), Lyon, France, pp. OA3-2. [Online]. Available: http://aimontefiore.org/emf2016/ProgramEMF2016.html 


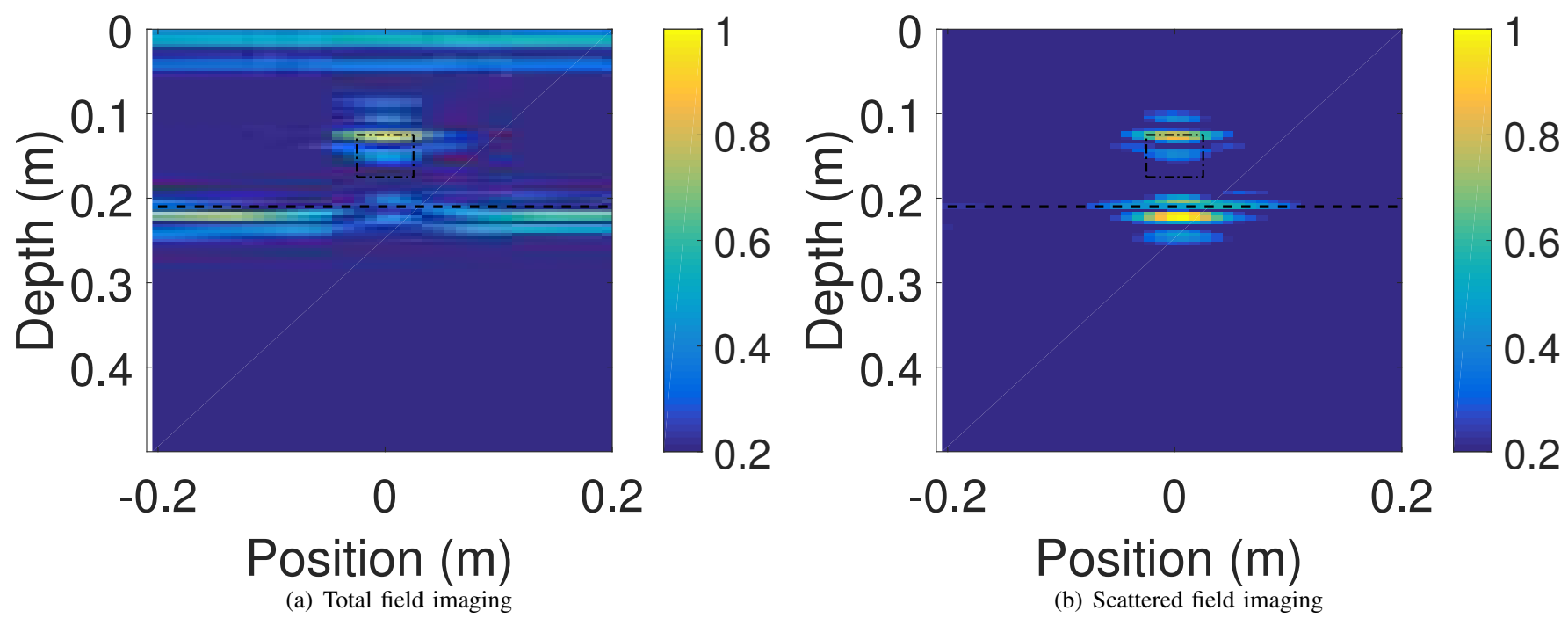

Fig. 11. KM imaging with a single buried object from measurement: the dash-dot contour present the exact position of buried objects, the dashed line is the bottom metal plate.

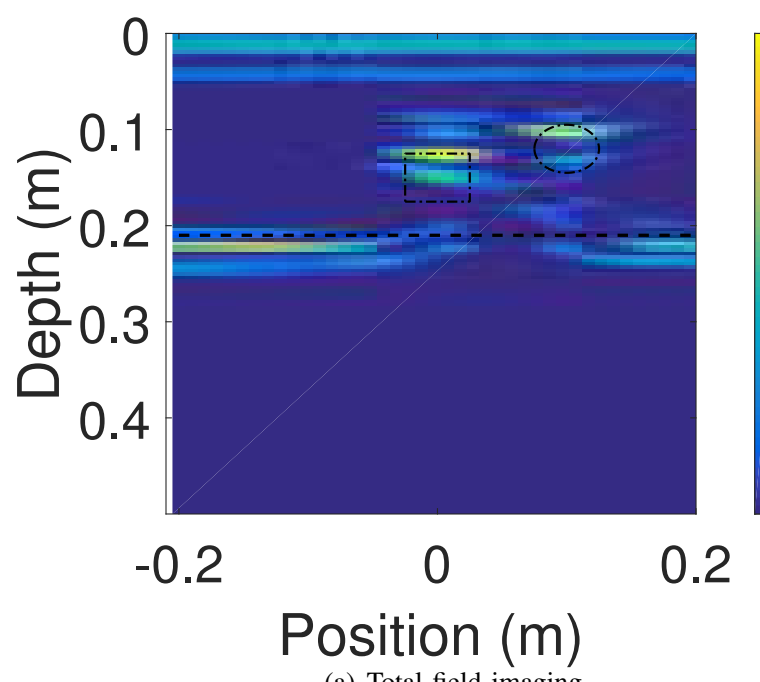

(a) Total field imaging
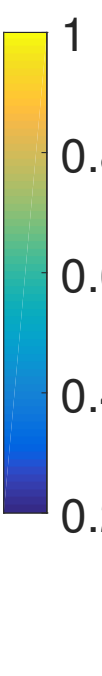

Fig. 12. KM imaging with two buried objects using measurements: the dash-dot contour present the exact position of buried objects and the dashed line the bottom metal plate. 